\title{
Distal Sensory Polyneuropathy among HIV Patients in Libreville in Gabon
}

\author{
Kouna-Ndouongo Philomène ${ }^{*}$, Adoukonou Thierry², Oura Landry33, Ibole James', \\ Assengone-Zeh Yvonne', Moubeka Mounguengui Martine' ${ }^{1}$, Mouangue Minso Gertrude ${ }^{1}$ \\ ${ }^{1}$ Service de Neurologie Centre Hospitalier Universitaire de Libreville, Libreville, Gabon \\ 'Unité d'Enseignement et de Recherche de Neurologie, Faculté de Médecine, Université de Parakou, Parakou, \\ Benin \\ ${ }^{3}$ Hôpital d'Instruction des Armées Omar Bongo Ondimba, Service de Neurologie, Libreville, Gabon \\ Email: ${ }^{\text {ndouongop@yahoo.fr }}$
}

Received 18 July 2015; accepted 22 August 2015; published 25 August 2015

Copyright (C) 2015 by authors and Scientific Research Publishing Inc.

This work is licensed under the Creative Commons Attribution International License (CC BY). http://creativecommons.org/licenses/by/4.0/

(c) $\underset{\mathrm{EY}}{\mathrm{B}}$ Open Access

\section{Abstract}

Distal sensory polyneuropathy (DSP) was more frequent among Human Immunodeficiency Virus (HIV) patients. The reliable tool for its diagnosis is not available everywhere in sub-Saharan Africa. We aimed to estimate the frequency of DSP among HIV patients in Libreville. We've conducted a cross-sectional study including all consecutives HIV-patients admitted to the HIV clinic in the University Teaching Hospital of Libreville (Gabon) between 1 May and 31 July 2014. All patients underwent a full neurological examination doing by two neurologists. The diagnosis of DSP was based on Brief Peripheral Neuropathy Screen (BPNS). We also collected the data concerning past medical history, the use of neurotoxic drug, history of disease and data of High Active Antiretroviral Therapy (HAART). The logistic regression was used to study the factors associated with DSP. They were 620 patients aged from 17 to 74 years with the mean age of 42.1 years \pm 11.0 years and $570(91.9 \%)$ were on HAART. The mean duration of disease was $57.6 \pm 42.5$ months. Among the 620 patients 170 fulfilled criteria for DSP, and the overall frequency of DSP was $27.4 \%$. The associated factors in univariate analysis were the age, the occupation, the use of HAART, the HAART option, the stage of the disease, opportunistic disease, alcohol consumption, exposure to isoniazid, diabetes mellitus and the modes of contamination. But in multivariate analysis the associated factors were the stage of disease OR 2.7 [1.2 - 3.7], diabetes mellitus OR 2.4 [1.4 - 5.8] and the use of D4T in HAART OR 1.9 [1.1 - 4.9]. The main symptoms among the patients were burning feet (47.6\%), the tingling $(40.0 \%)$, numbness $(27.6 \%)$, alteration of ankle reflex $(87.6 \%)$ and alteration of vibration sensation (27.6\%). The DSP was more frequent among HIV patients and could be explained by the duration of the disease, the association with metabolic disease and the use of D4T.

"Corresponding author.

How to cite this paper: Philomène, K.-N., Thierry, A., Landry, O., James, I., Yvonne, A.-Z., Martine, M.M. and Gertrude, M.M. (2015) Distal Sensory Polyneuropathy among HIV Patients in Libreville in Gabon. Neuroscience \& Medicine, 6, 84-89. 


\section{Keywords}

Distal Sensory Polyneuropathy, HIV, HAART, Epidemiology, Sub-Saharan Africa, Frequency

\section{Introduction}

In Gabon, the prevalence of Human Immunodeficiency Virus (HIV) infection in adults between 15 and 49 years was $4.0 \%$ in 2012 and the part of mortality due to AIDS (Acute Immunodeficiency Syndrome) was 2300 deaths [1]. The peripheral nervous system infection by HIV is very common and can affect all stages of infection [2]. All forms of neuropathy can meet and at all stages [3]. Many pathophysiological mechanisms can affect the peripheral nervous system. The HIV can affect directly the dorsa root ganglions neurons, the infiltration of activated macrophage which secrets the neurotoxins cytokines and other toxic metabolites. The neurotoxic action of the antiretroviral drugs can explain some parts of the distal sensory polyneuropathy (DSP). The distal sensory polyneuropathy is the most frequent forms [4]. Factors associated with them are the virus itself, opportunistic infections (cytomegalovirus, which rather gives multiple mononeuropathies) and antiretroviral therapy [3] [5]-[7]. The prevalence of sensory polyneuropathy varies greatly according to the criteria used, and may reach $50 \%$ [8]-[11]. In Africa the unavailability of electromyography makes diagnosis more difficult, often based on clinical criteria. But in recent years an American team has developed a purely clinical diagnostic tool to diagnose the polyneuropathy [12]. This is the Brief Peripheral Neuropathy Screen (BPNS) with good diagnostic validity [13]-[15]. In Africa a few studies have used this tool [8]-[10]. In Gabon there are not to our knowledge the reliable data on the distal sensory polyneuropathy.

The objective of this study was to investigate the frequency of distal sensory polyneuropathy in people living with HIV.

\section{Methods}

\subsection{Setting}

The study took place at the University Teaching Hospital of Libreville in its HIV patients Clinic. It is the most important clinic of the HIV patients in the country and about 700 patients were followed. Four physicians (specialists in HIV management) and 11 nurses worked in the clinic. All the patients were followed ambulatory and those who needed hospitalization were managed at the Infectious diseases clinic or Internal Medicine Department.

\subsection{Type}

It was a cross-sectional study carried out from 1 May to 31 July 2014.

\subsection{Patients}

All consecutives patients admitted to the clinic during the study period and giving their consent were included. We also excluded all pregnant patients. All patients were undergone the full neurological examination doing by two neurologists (Kouna Philomène and Oura Landry)

\subsection{Variables}

The main variable was the distal sensory polyneuropathy with two modalities. The DSP was defined according to BPNS criteria [13].

Previously the initial version of BPNS was translated in French and back translated in order to ensure a good accuracy.

A neurological examination was performed in all patients and included seeking sensory symptoms, the study of superficial and vibration sensitivities (review in tune to $128 \mathrm{~Hz}$ ), the study of tendon reflexes. The examination is conducted by two neurologists previously trained in the use of BPNS scale.

According to the BPNS, the patient was recognized as having a distal sensory polyneuropathy if he had a 
sensory symptoms and one of the following two criteria:

- A reduction or abolition of the vibratory sensation in one or two big toes;

- A reduction or abolition of one or both ankle reflexes.

Is considered with symptomatic polyneuropathy any patient meeting the criteria changed BPNS and having at least a score of 1 at the sensory symptoms.

The exposure variables recorded were the:

- Socio-demographics data (age, sex, matrimonial status, profession...);

- Alcohol consumption and tobacco use;

- Clinical features (height, weight, body mass index, stage of the disease);

- Other opportunistic disease;

- The past medical history (diabetes mellitus, renal failure, viral hepatitis B and C);

- Exposure to drugs (metronidazole, isoniazid, hydroxyurea...);

- Therapeutic data : high active antiretroviral therapy (drugs and duration);

- Disease data: duration, CD4 rate, viral load...

\subsection{Statistical Methods}

The Statistical Package for Social Science (SPSS) version 22.0 software was used to perform statistical analysis. Usual descriptive analysis was used: means and standard deviations and frequencies. Chi-2 test (or exact test of Fisher) was used to test association between DSP and exposure variables. To study the variables strongly associated to the DSP the multivariable analysis were performed by using logistic regression model. Descending step by step procedure has been established and the odds ratio (OR) and its confidence interval (CI) at $95 \%$ were estimated. For all analysis the level of significance was fixed at $\mathrm{p}<0.05$.

\subsection{Ethical Issues}

The study was approved by the local health authority and anonymity and confidentiality were observed. All patients had given their verbal consent before inclusion.

\section{Results}

During the study period 683 patients were seen and 620 were included. The participation rate was $90.8 \%$. They aged form 17 to 74 years with the mean age of 42.1 years \pm 11.0 years. They were 144 males $(23.2 \%)$ with sex-ratio of 0.3 . The Christians represented $88.1 \%$ of the sample and 208 (33.5\%) were unemployed. About $65.8 \%$ of the patients had a level of instruction more than the secondary school and according to marital status $51.9 \%$ were alone (widowed, divorced or single).

The disease duration was 0 to 234 months with the mean of $57.6 \pm 42.5$ months.

Among the 620 patients 462 (74.5\%) had a least one opportunistic disease and 570 (91.9\%) were on HAART. The main combination used contained 3TC and Efavirenz and the association 3TC+ Efavrirenz were used in 424 patients $(68.4 \%)$.

Among the 620 patients 170 had fulfilled criteria for DSP; the overall prevalence of DSP was $27.4 \%$.

The sex $(p=0.3)$, the marital status $(p=0.6)$ the level of instruction $(0.09)$, the religion $(p=0.55)$, the body mass index $(p=0.7)$, the use of metronida zole $(p=0.06)$, the use of tobacco $(p=0.2)$ and the past medical history of zona $(p=0.6)$ were not statistically associated to DSP in univariate analysis.

The main factors associated to DSP in univariate analysis were summarized in Table 1.

In multivariate analysis the associated factors were diabetes mellitus, the stage of disease and the type of HAART (Table 2).

The main reported symptoms among patients with DSP were the pain (all) and paresthesia such as burning, tingling, numbness. Some of them had had a hypoesthesia and diminution of ankle reflex. Only 2 patients had motor weakness. The clinical data are summarized in Table 3.

\section{Discussion}

We've conducted a cross-sectional study and aimed to estimate the frequency of distal sensory polyneuropathy among HIV patients in Libreville. The design of study was appropriate and the sample size could be considered 
Table 1. Factors associated to Distal Sensory Polyneuropathy among HIV patients in Libreville in Gabon, 2014.

\begin{tabular}{|c|c|c|c|c|}
\hline Variables & DSP N (\%) & No DSP N & OR [CI 95\%] & $\mathrm{p}$ \\
\hline \multicolumn{5}{|l|}{ Age (years) } \\
\hline$\leq 40$ & $16(5.3)$ & 286 & 1 & $<10^{-7}$ \\
\hline$>40$ & $154(48.4)$ & 164 & $16.8[9.4-30.3]$ & \\
\hline Occupations & & & & 0.01 \\
\hline Low job & $28(21.5)$ & 102 & 1 & \\
\hline Trader & $24(24.5)$ & 74 & $1.2[0.6-2.3]$ & \\
\hline Unemployed & $54(26.0)$ & 154 & $1.3[0.7-2.2]$ & \\
\hline Student & $20(34.5)$ & 38 & $1.9[0.9-4.0]$ & \\
\hline Active worker & $44(34.9)$ & 82 & $2.0[1.1-3.5]$ & \\
\hline Use of HAART & & & & 0.037 \\
\hline Yes & $150(26.3)$ & 420 & 1 & \\
\hline No & $20(40.0)$ & 30 & $1.9[1.0-3.52]$ & \\
\hline HAART option & & & & 0.0004 \\
\hline Without D4T & $142(25.4)$ & 418 & 1 & \\
\hline With D4T & $28(46.7)$ & 32 & $2.6[1.4-4.6]$ & \\
\hline Stage of disease & & & & 0.003 \\
\hline Stade A & $34(16.0)$ & 178 & 1 & \\
\hline Stade B & $30(26.3)$ & 84 & $1.9[1.0-3.4]$ & \\
\hline Stade C & $106(36.0)$ & 188 & $2.9[1.9-4.7]$ & \\
\hline \multicolumn{5}{|l|}{ Opportunistic disease } \\
\hline No & $18(11.4)$ & 140 & 1 & $<10^{-7}$ \\
\hline Yes & $152(32.9)$ & 310 & $3.8[2.2-6.7]$ & \\
\hline Duration of disease (months) & & & & 0.05 \\
\hline$\leq 60$ & $104(25.2)$ & 308 & 1 & \\
\hline$>60$ & $66(31.7)$ & 142 & $1.4[0.9-2.0]$ & \\
\hline Alcohol consumption & & & & 0.002 \\
\hline No & $102(23.8)$ & 326 & 1 & \\
\hline Yes & $68(35.4)$ & 124 & $1.8[1.2-5.6]$ & \\
\hline Exposure to Isoniazid & & & & 0.001 \\
\hline No & $120(24.5)$ & 370 & 1 & \\
\hline Yes & $50(38.5)$ & 80 & $1.9[1.3-3.0]$ & \\
\hline Diabetes mellitus & & & & 0.00002 \\
\hline No & $162(26.5)$ & 450 & 1 & \\
\hline Yes & $8(100.0)$ & 0 & $3.8[3.3-4.3]$ & \\
\hline Mode of contamination & & & & 0.00007 \\
\hline Sexual & $130(24.1)$ & 410 & 1 & \\
\hline Other & $36(45.0)$ & 44 & $2.6[1.6-4.3]$ & \\
\hline
\end{tabular}

Table 2. Factors associated to DSP in multivariate analysis using logistic regression, Libreville 2014.

\begin{tabular}{|c|c|c|}
\hline Variables & OR [CI 95\%] & $\mathrm{p}$ \\
\hline Stage C (yes/no) & $2.7[1.2-3.7]$ & 0.01 \\
\hline Diabetes Mellitus (yes/no) & $2.4[1.4-5.8]$ & 0.04 \\
\hline Use of D4T (yes/no) & $1.9[1.1-4.9]$ & 0.01 \\
\hline
\end{tabular}


Table 3. Clinical features of the 170 HIV patients with distal sensory polyneuropathy, Libreville 2014.

\begin{tabular}{ccc}
\hline Clinical signs & Number & Percentage \\
\hline Paresthesia* & & 47.6 \\
Burning & 81 & 40.0 \\
Tingling & 68 & 27.6 \\
Numbness & 47 & 47.1 \\
Grade of sensory symptoms & & 34.7 \\
Grade 1 & 80 & 18.2 \\
Grade 2 & 59 & 27.6 \\
Grade 3 & 31 & 87.6 \\
Alteration of vibratory sensation & 47 & 149 \\
Diminution or abolition of ankle reflex
\end{tabular}

*Some patients had more than one sensory symptom.

as more representative of this population. Indeed the participation rate of $90.8 \%$ was excellent. To study the distal sensory polyneuropathy we used one clinical tool which had a good accuracy in previous studies [13]-[15]. In order to study the associated factors to DSP we performed a multivariate analysis by using logistic regression which is the best model for this estimation.

The frequency of DSP in our study was $27.4 \%$. It was less than other reported in various countries in Africa [8]-[11] [16]. The difference could be explained by the sample size, the mean age of the populations, the proportion of population on HAART and the diagnosis tool used by authors. Compared to the other studies the patients who undertook HAART had less risk for DSP. The high rate of the patients on HAART and the difference between the drugs used in those countries can explain this difference. In this study patients were older than the patients in Parakou [16] (42.1 years versus 36.8 years). We found a relation between age and DSP. The advanced age exposes peripheral nervous system to many factors such as metabolic disease, microvascular disease. In this hypothesis the diabetes mellitus was associated to the DSP in our study. We had showed that the duration of disease and the opportunistic disease increased the risk of DSP. Those factors might be the confounding factors as far as they were associated to the age. Despite that the use of HAART had a protect effect against DSP. Nevertheless the HAART containing D4T was associated to DSP. It is well known that the stavudine can increase a risk for polyneuropathy [2] [5]. But only 60 patients had used D4T for many reasons. The low use of D4T in the HAART drugs can also explain the low frequency of DSP among HIV infected patients in Libreville. The association between D4T and DSP was not seen in the Parakou study. In this study about $35.5 \%$ of the patients on HAART were used stavudine. Nevertheless no association was found between the use of this drug and the presence of DSP. Despite that they found high frequency of DSP. We can make a hypothesis that other factors can explain the occurrence of DSP among HIV infected patients such as the duration of disease due to the vulnerability of the nervous system, the association with the metabolic disease. What concerning the duration of the disease it is well known that at the end stage of the disease all patients had peripheral nervous disorder. The other factors associated in univariate analysis were probably the confounding factors. More data are available on the association between alcohol, use of neurotoxic drug such as isoniazid and metronidazole and neuropathy. But in our study those factors were not seen associated to DSP. The use of the logistic regression model helps us to eliminate the confounding factors. Then the specifically factors which can explain the DSP were only seen. In summary distal sensory polyneuropathy was frequent and can be explained by the high proportion of diabetics, the use of D4T and the stage of disease. It will be very important to take part of those factors in order to reduce the burden of distal sensory polyneuropathy and improve the quality of life of HIV-infected patients. It is very important for the prevention of the DSP to screen diabetes mellitus in HIV-infected patients and to limit the use of D4T in the antiretroviral therapy.

\section{Conclusion}

The distal sensory polyneuropathy is more frequent among HIV-infected patients in Libreville. It could be ex- 
plained by the stage of the disease, the use of D4T in the antiretroviral therapy and the association with diabetes mellitus.

\section{References}

[1] Tack, I. (2012) Estimations VIH et SIDA [Online]. ONUSIDA. http://www.unaids.org/fr/regionscountries/countries/gabon

[2] McArthur, J., Brew, B. and Nath, A. (2005) Neurological Complications of HIV. The Lancet Neurology, 4, 543-555. http://dx.doi.org/10.1016/S1474-4422(05)70165-4

[3] Verma, A. (2001) Epidemiology and Clinical Features of HIV-1 Associated Neuropathies. Journal of the Peripheral Nervous System, 6, 8-13. http://dx.doi.org/10.1046/j.1529-8027.2001.006001008.x

[4] Bacellar, H., Munoz, A., Miller, E., et al. (1994) Temporal Trends in the Incidence of HIV-1-Related Neurologic Diseases: Multicenter AIDS Cohort Study, 1985-1992. Neurology, 44, 1892-900. http://dx.doi.org/10.1212/WNL.44.10.1892

[5] Dalakas, M.C. (2001) Peripheral Neuropathy and Antiretroviral Drugs. Journal of the Peripheral Nervous System, 6, 14-20. http://dx.doi.org/10.1046/j.1529-8027.2001.006001014.x

[6] Said, G., Lacroix, C., Chemouilli, P., et al. (1991) Cytomegalovirus Neuropathy in Acquired Immunodeficiency Syndrome: A Clinical and Pathological Study. Annals of Neurology, 29, 139-146. http://dx.doi.org/10.1002/ana.410290205

[7] Keswani, S.C., Pardo, C.A., Cherry, C.L., et al. (2002) HIV-Associated Sensory Neuropathies. AIDS, 16, $2105-2117$. http://dx.doi.org/10.1097/00002030-200211080-00002

[8] Maritz, J., Benatar, M., Dave, J.A., et al. (2010) HIV Neuropathy in South Africans: Frequency, Characteristics, and Risk Factors. Muscle Nerve, 41, 599-606. http://dx.doi.org/10.1002/mus.21535

[9] Mullin, S., Temu, A., Kalluvya, S., Grant, A. and Manji, H. (2011) High Prevalence of Distal Sensory Polyneuropathy in Antiretroviral-Treated and Untreated People with HIV in Tanzania. Tropical Medicine \& International Health, 16, 1291-1296. http://dx.doi.org/10.1111/j.1365-3156.2011.02825.x

[10] Shurie, J.S. and Deribew, A. (2010) Assessment of the Prevalence of Distal Symmetrical Polyneuropathy and Its Risk Factors among HAART-Treated and Untreated HIV Infected Individuals. Ethiopian Medical Journal, 48, 85-93.

[11] Evans, D., Takuva, S., Rassool, M., Firnhaber, C. and Maskew, M. (2012) Prevalence of Peripheral Neuropathy in Antiretroviral Therapy Naïve HIV-Positive Patients and the Impact on Treatment Outcomes-A Retrospective Study from a Large Urban Cohort in Johannesburg, South Africa. Journal of NeuroVirology, 18, 162-171. http://dx.doi.org/10.1007/s13365-012-0093-2

[12] Simpson, D.M., Kitch, D., Evans, S.R., McArthur, J.C., Asmuth, D.M., Cohen, B., et al. (2006) ACTG A5117 Study Group. HIV Neuropathy Natural History Cohort Study: Assessment Measures and Risk Factors. Neurology, 66, 16791687. http://dx.doi.org/10.1212/01.wnl.0000218303.48113.5d

[13] Cherry, C.L., Wesselingh, S.L., Lal, L. and McArthur, J.C. (2005) Evaluation of a Clinical Screen Tool for HIV Associated Sensory Neuropathies. Neurology, 65, 1778-1781. http://dx.doi.org/10.1212/01.wnl.0000187119.33075.41

[14] Marra, C.M., Boutin, P. and Collier, A.C. (1998) Screening for Distal Sensory Peripheral Neuropathy in HIV-Infected Persons in Research and Clinical Settings. Neurology, 51, 1678-1681. http://dx.doi.org/10.1212/WNL.51.6.1678

[15] McArthur, J.H. (1998) The Reliability and Validity of the Subjective Peripheral Neuropathy Screen. Journal of the Association of Nurses in AIDS Care, 9, 84-94. http://dx.doi.org/10.1016/S1055-3290(98)80048-4

[16] Kpacha, B. (2011) Prévalence des neuropathies périphériques et facteurs associes chez les personnes vivant avec le VIH suivies au centre hospitalier départemental et universitaire de Parakou. Medical Thesis No. 119, Parakou (BENIN). 